\title{
Dental Treatment for a European Red Tail Deer
}

\author{
Raluca-Ioana NEDELEA ${ }^{1 *}$, Adrian TOMA² ${ }^{2}$ Andreea MĂRINCUȘ² \\ ${ }^{1}$ DentoVet, Cluj-Napoca, Romania; \\ ${ }^{2}$ DVM, Calvaria Veterinary Clinic, Cluj-Napoca; \\ * corresponding author: Raluca.Nedelea@dentovet.ro
}

Bulletin UASVM Veterinary Medicine 77(2)/2020

Print ISSN 1843-5270; Electronic ISSN 1843-5378

doi:10.15835/buasvmcn-vm:2020.0026

\begin{abstract}
The veterinarian doctor has to be prepared to help various kind of species. Our team had to perform dental treatment for a five years old European red tail deer. The deer was eating with difficulty. Even thou it was a hot summertime, the hind presented late shedding. Her calm and kind behaviour changed into an aggressive one. She was biting cold, metal objects, obviously to calm her dental pain. Our approach aimed to re-establish the biological and physiological balance of the oral cavity. A thorough general exam was performed for differential diagnosis. Oral examination revealed an aggressive periodontal disease. Surgical extractions were the only possible treatment. One year follow up is good, changing the prognosis from a reserved one into very good.
\end{abstract}

Keywords: dentistry, deer, periodontolohy, extractions

\section{Introduction}

The variety of pets is diversifying every day. The veterinarian doctor has to be prepared to help multiple species to obtain proficiency in this profession. The patient is a five-years-old hind of Carpathian Mountains Red Tail Deer. It was bought from the black meal market when it was about four-months-old. Some peasants captured the baby and sold it for the meat. In Romania, deers are not allowed to be raised as pets. But, the owner opened a trial and won its custody legally.

At the beginning of 2019's summer, when the hind was five-years-old: hind's appetite decreased severely. Our patient started to lose weight. Another clinical sign, pleading for dental pain was the fact that the hind started to bite cold metal objects, obviously to calm her front teeth' dental pain. Meanwhile, her kind and gentle behaviour became aggressive. The hind was experiencing episodes of pain with minutes of yawning. Even thou it was full summertime, with high temperatures, her coat was still shedding, unlike other years.

\section{Materials and methods}

The first major challenge was to find out more about dental procedures worldwide, in deers. The only thing that can be found about this subject is the correlation between the age, gender, subspecies, deer teeth' morphology, dental chart and teeth eruption patterns (Perez-Barbeira, Carranza, Prieto 2015). All these studies were made on shot deers, not giving a single clue about improving quality of life by performing dental procedures in deers or ruminants.

Dental chart for an adult Cervidae is:

$$
2 \times \frac{\mathrm{I}: 0, \mathrm{C}: 0, \mathrm{PM}: 3, \mathrm{M}: 3}{\mathrm{I}: 3, \mathrm{C}: 1, \mathrm{PM}: 3, \mathrm{M}: 3}
$$

Last teeth that erupt are the third molars that usually happens somewhere after 30 months in the United States. Europeans reported an average of 40-42 months on the same issue. (Azorit, 2002) In order to prepare us properly for the intervention, we exposed the dental roots on a deer's skull. 
One may say that the coronal part is adapted to their nutrition and that the root anatomy and the endodontics were quite similar to humans.

The upper jaw of the ruminants has no incisors or canines, having just a dental pad. The dental pad is a hard gum where the animal can pinch blades of grass with the bottom incisors. The canines of the lower jaw look just like the other incisors. Usually, the frontal teeth of the deer are the first ones lost, as their periodontal ligament is very loose.

The particularities of the deer mouth are notable and very important for the whole intervention: small mouth opening and in-depth situated teeth. Gas anaesthesia is impossible as endotracheal intubation is not possible. Due to local conditions, general anaesthesia was medically induced.

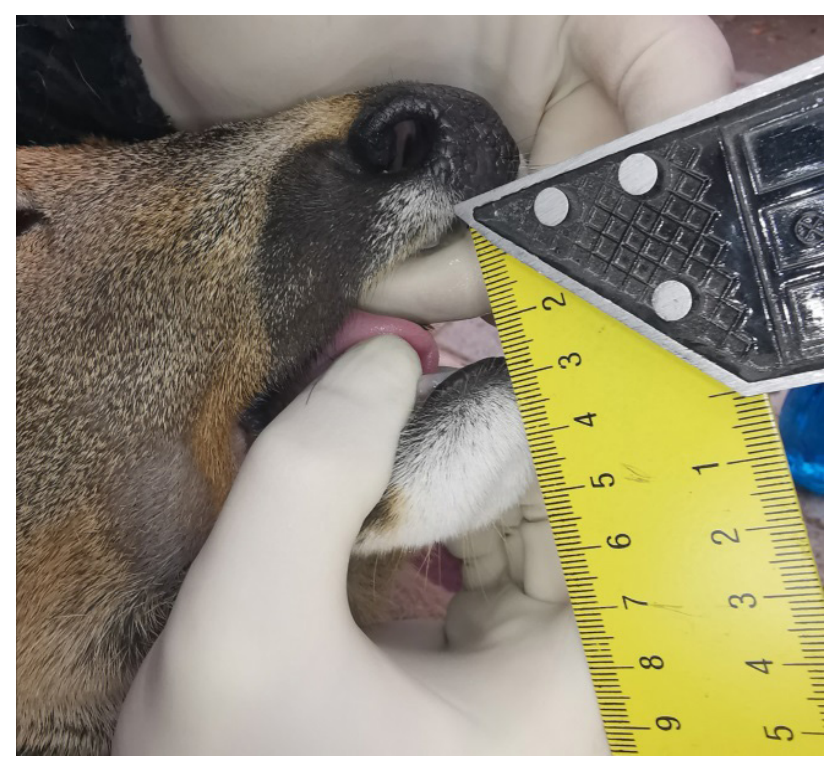

Figure 1. Small mouth opening in a deer (dr. Raluca Nedelea's personal archive)

The particularities of the deer mouth are notable and very important for the whole intervention: small mouth opening and in-depth situated teeth. Gas anaesthesia is impossible as endotracheal intubation is not possible. Due to local conditions, general anaesthesia was medically induced.

Total weight of the deer was estimated to 25 kilograms. Preanaestesia was induced IM injection $30 \mathrm{mg}$ xylazine, that is the equivalent of $1,2 \mathrm{mg} /$ bodyweight xylazine. Maximum effect was onset in 10-15 minutes after injection. The hind adopted the sternoabdominal position. It could move the head, but could not react to manipulation. A venous line was set on the lateral saphenous vein. A Ringer solution was administered one drop/ second. Anaesthesia was induced bolus IV made of $0.08 \mathrm{mg} / \mathrm{kg}$ body weight and $2 \mathrm{mg} / \mathrm{kg}$ body weight ketamine. Endotracheal intubation was not possible because of the long, thin larynx and because of the limited mouth opening. Plus, the dental procedures could not have been possible in such little space.

The intervention took place outside, so the monitoring of the pulse, cardiac frequency and the breathing was performed by observation with the help of stethoscope and thermometer. Maintaining the anaesthesia was obtained by administering every 20-30 minutes (direct correlation with the cardiac and respiratory frequency and members movement) four times a bolus IV made of $0.5 \mathrm{mg} / \mathrm{kg}$ body weight and $0.03 / \mathrm{kg}$ bodyweight diazepam. After three hours and a half from the first administrations of xylazine, the deer received IM $0.04 \mathrm{mg} / \mathrm{kg}$ body weight atipamezole. The full recovery of our patient happened 10 minutes after administration of atipamezole. Throughout the intervention, the respiratory frequency was around 24-30/minute, cardiac pulse was around 53-70/ minute, and the temperature was always around 37.5 Celsius.

Oral examination revealed us an aggressive periodontal disease, stage 4 (PD4), with almost all furcations exposed, so we had stage 3 furcation involvement in multirooted teeth, mobility index was stage 3 (M3), except third upper molars and a right side third lower molar where mobility was stage 2. Notable recessions at multirooted teeth were present associated with large amounts of dental plaque and calculus on the coronal parts and even until the top of the exposed roots. The alveolar gingiva had spontaneous bleeding and severe inflammation. Also halitosis was present.

Frontal mandibular teeth were fractured 2-3 $\mathrm{mm}$ above the gingiva with dental pulp exposed. We would have considered a reconstruction for them if the periodontal disease hadn't been present. Thus, a decision for subtotal mouth extractions was made. Due to the local situation (small opening of the mouth, non-retractable cheeks and lips and in-depth situated teeth) we had to come up with creative ideas to manage to accomplish our goals. 


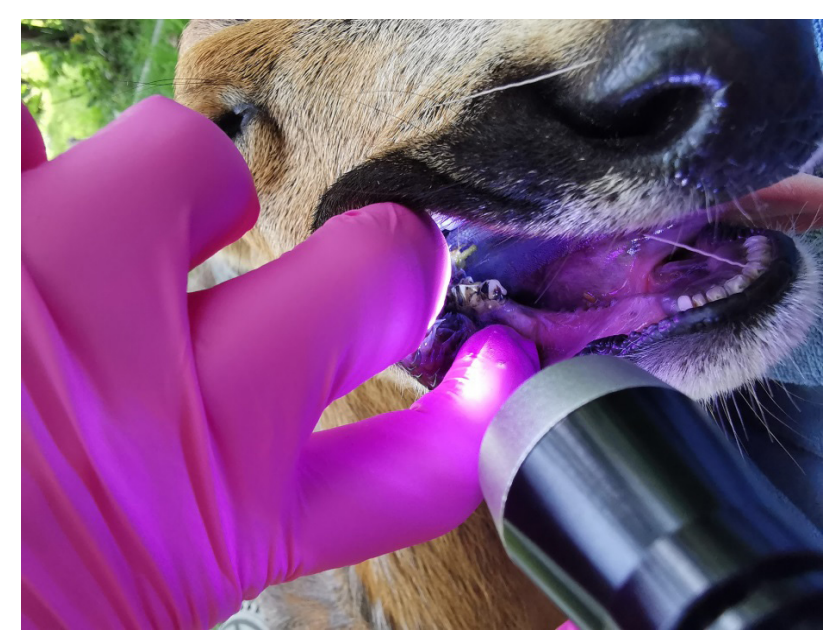

Figure 2. Oral examination of our patient (dr. Raluca Nedelea's personal archive)

Local anaesthesia was obtained by intraligamentar injection of small amounts of $40 \mathrm{mg}$ articaine chlorhidrate/ 5 microgrammes epinephrine/ ml. Maximum $0.4 \mathrm{ml} /$ tooth, as the maximum amount of articaine is $0,175 \mathrm{ml} / \mathrm{kg}$ body weight.

From human dentistry, we have helped us with curved mandibular pair elevators (left and right), dental forceps for trismus, and of course Hemingway bone curette as seen in the images. The sutures were resorbable, PGA 4.0.

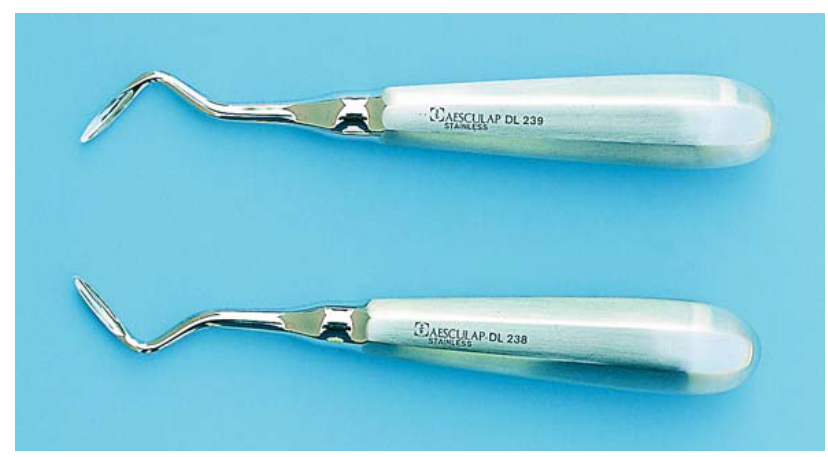

Figure 3. Curved mandibular elevators, left and right

Nine months after the first intervention, we were asked again for extractions of the remaining teeth. The hind refused food, also experienced episodes of yawning, lost weight, and her medical condition was poor. General anaesthesia was induced as seen before. Oral examination revealed that all of our previous extractions healed good, as it can be seen in the photos below.

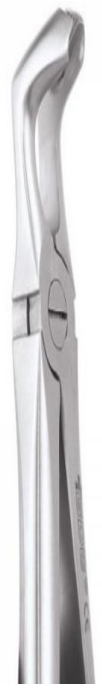

Figure 4. Dental forceps indicated in trismus

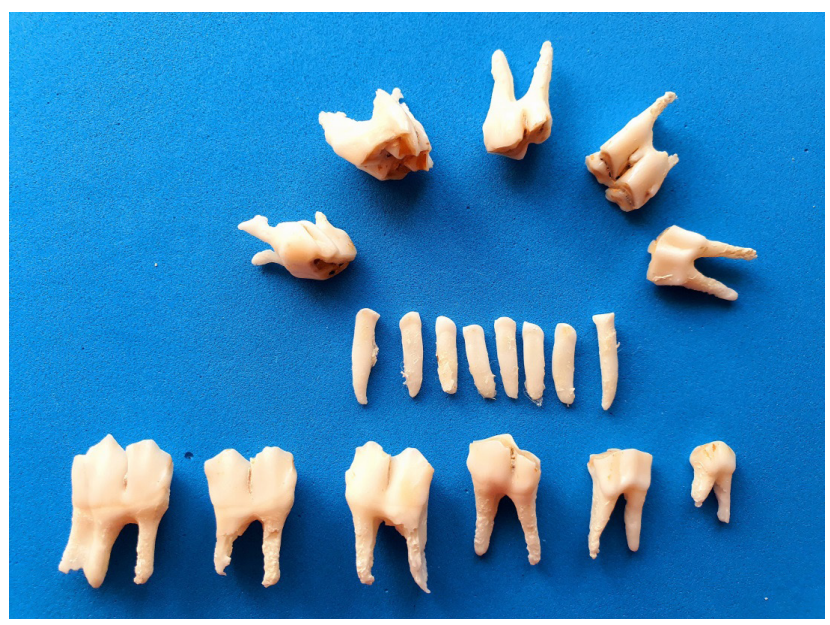

Figure 5. Extracted teeth

(dr. Raluca Nedelea's personal archive)

Periodontal disease continued its evolution at the remaining teeth, involving the furcation, inducing mobility stage 3 . The coronal part as well the exposed radicular part were covered with dental plaque and calculus. The marginal gingiva and the alveolar gingiva next to the affected teeth were spontaneously bleeding, red coloured and had a modified structure. All of these clinical signs explained the indirect, clinical signs of dental pain.

\section{Results and discussions}

Our patient started to eat the second day after dental treatment. Her behaviour changed into a gentle one again. She had episodes of happiness while she was dancing and running happily. Our 
main concern was, after the surgical extractions, the adaptation to the new life without dental units as a ruminant. A risk of ruminal atony or tympany was the worst scenario. One year follow up is good, changing the prognosis from a reserved one into very good.

Periodontal disease was closely studied in humans. Veterinary dentistry has an essential

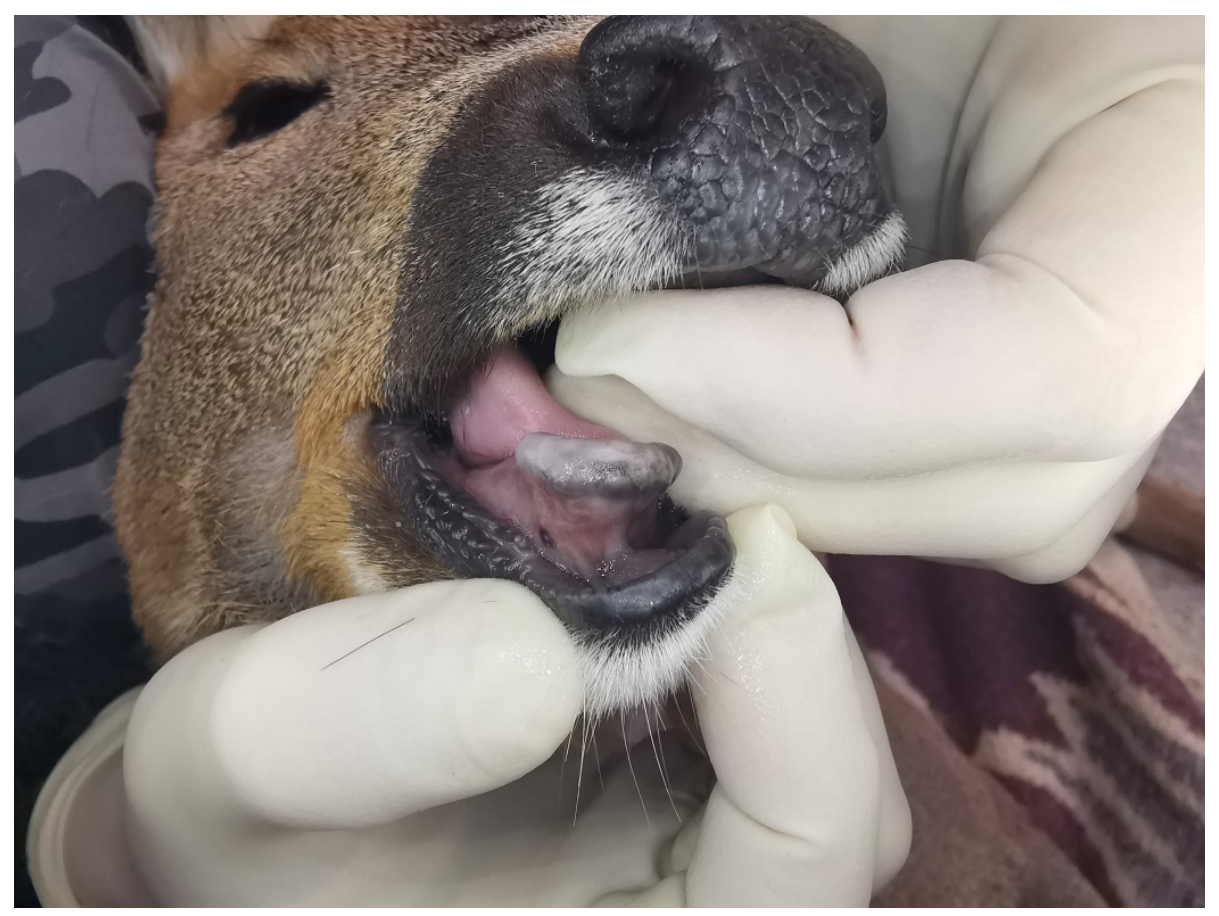

Figure 6. Frontal mandibular healing, 9 months after surgical extractions performed (dr. Raluca Nedelea's personal archive)

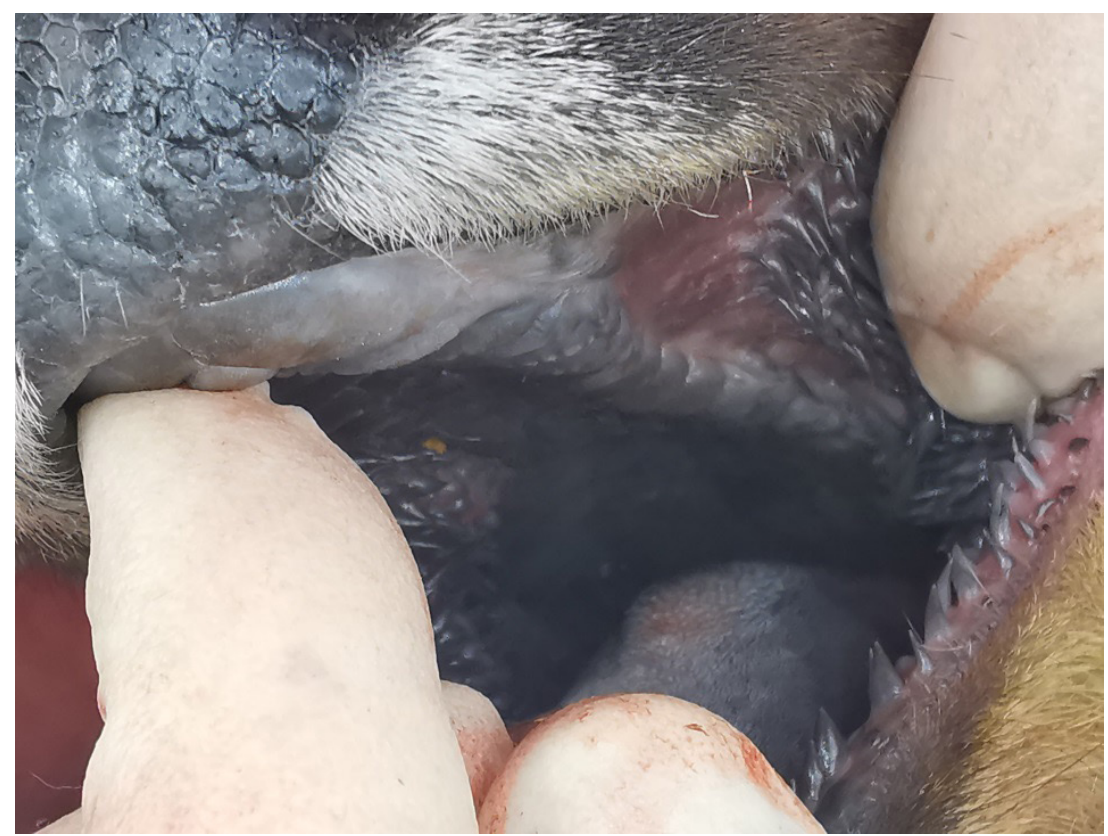

Figure 7. Caudal maxillary gingival healing 9 months after surgical extractions performed in a deer (dr. Raluca Nedelea's personal archive) 
chapter regarding periodontology in cats and dogs. (Niemiec, 2013) There are different studies made upon wild felines confirming the universality of periodontal disease. (Andrade et al., 2015) Our case is the first one worldwide reporting periodontal disease in deer and dental procedures on a deer. All of the dental studies were made on dead animals, none of them involving dental treatments. It would have been easier for us to be able to get some more information about this subject. However, getting out of one's comfort zone is the first step to evolution.

The veterinarian has to be prepared to be creative and to find innovative solutions for different patients. Continuous medical education is imperative. The range of pet species increases every day. In a world full of stress, people find an isle of peace in their pets, investing a lot of affection in them. The average of life for deer is somewhere around 16-20 years of life. Educating people about the importance of veterinary dentistry is one of the keys to success. We have to understand that oral pathology has a significant percentage in the morbidity of veterinary patients. Low studied fields do not mean that they do not exist. We have to open our mind in order to be prepared to offer high-quality services and to accept the everyday professional challenges.

\section{Conclusions}

Periodontal disease is present in humans, canine and feline species and, as we can see, even in Cervidae. There are different studies made on wild animals regarding the universal presence of periodontal disease in mammals. (Andrade et al., 2015) By now, it is well known that the lack of dental hygiene will lead to dental plaque accumulation on the dental surface. The dental plaque will induce a gingival inflammation, and the whole circle of periodontal disease will be started leading to the loss of dental units involved. In the wilderness, dental pain and dental units lost lead to no feeding properly, losing weight and becoming a safe prey for the predators. Circle of life in nature starts and ends in its own way, every day. We still have a lot to learn and to understand its rules.

Acknoledgments. This research did not receive any specific grant from funding agencies in the public, commercial, or not-for-profit sectors.

\section{References}

1. Andrade P, Morgado T, Mallmann P, Spiller P, GomesL, StoccoM, Martini A, SchroderD, CorreaS, Souza R (2015). Occurrence of oral diseases in neotropical wild carnivores kept in captivity at the zoo from Federal University of Mato Grosso - Cuiabá. Semina: Ciências Agrárias. 36. 2633. 10.5433/1679-0359.2015v36n4p2633.

2. Azorit C, Analla M, Carrasco R, Calvo JA, Munoz-Cobo Joaquin (2002). Teeth eruption pattern in red deer(Cervus elaphus hispanicus) in southern Spain. Anales de biologia 24:107-114.

3. Niemiec $A B(2013)$. Veterinary Periodontology. ( $1^{\text {st }}$.ed.). Wiley\&Blackwell, (Chapter 1, 2).

4. Perez-Barbeira FJ, Carranza J, Sanchez-Prieto C ( 2015). Wear fast, die young :more worn teeth and shorter lives in Iberian compared to Scottish red deer. PLoS ONE 10 (8): E0134788.doi:10.1371/journal.pone.0134788. 